\title{
Metoprolol Significantly Improves Visual Clarity and Hemodynamic Parameters during Functional Endoscopic Sinus Surgery
}

\author{
Ahmed A. Sadek ${ }^{a} \quad$ Mokhtar Mostafa $^{b} \quad$ Tarek Abdel-Monem $^{b}$ \\ a Otorhinolaryngology Department, Faculty of Medicine, Minia University, Minia, Egypt; \\ ${ }^{\mathrm{b}}$ Anesthesiology and Intensive Care Department, Faculty of Medicine, Minia University, \\ Minia, Egypt
}

What Is It about?

- $\quad$ Controlled hypotension has many advantages for functional endoscopic sinus surgery (FESS) including reduction in blood loss and improved quality of the surgical field. This study determined whether the use of a $\beta$-blocker (metoprolol) as a premedication could improve the operative field in FESS. Sixty patients, undergoing septoplasty and FESS were included in this prospective, randomized, double-blind, placebo-controlled study. Patients were randomly assigned to receive either metoprolol (100 mg) or a vitamin tablet $60 \mathrm{~min}$ before surgery. The surgical field was significantly clearer, and the mean arterial blood pressure and heart rate were also significantly lower in the metoprolol group.

\section{Keywords}

Metoprolol $\cdot$ Endoscopic sinus surgery $\cdot$ Hemodynamics

\section{Abstract}

Background and Objectives: The success of functional endoscopic sinus surgery (FESS) depends on the visual clarity of the surgical field, which is understudied. Controlled hypotension has many advantages for FESS including reduction in blood loss and improved quality of the surgical field. This study determined whether the use of $\beta$-blockers as a premedication could improve the operative field in FESS. Methods: Sixty patients aged from 18 to 50 years, undergoing septoplasty and FESS were included in this prospective, randomized, double-blind, placebo-controlled study. Patients were randomly assigned to receive either metoprolol (100 mg, group 1) or a placebo (a vitamin tablet, group 2) 60 min before surgery. Results: The average blood loss and surgery duration were not significantly higher in the placebo group. The 
surgical field was graded using the Fromme-Boezaart scale, and it was significantly clearer $(p<0.001)$ in metoprolol group. The mean arterial blood pressure was significantly lower in the metoprolol group after $30 \mathrm{~min}$ of induction until the end of surgery $(p<0.001)$. The heart rate was also significantly lower $(p<0.001)$ in those who received metoprolol from before induction of anesthesia up to the end of surgery. Conclusion: Metoprolol significantly improves visual clarity and hemodynamics during FESS. We would recommend the use of metoprolol in FESS and septoplasty.

(C) 2019 The Author(s)

Published by S. Karger AG, Basel

\section{Introduction}

Functional endoscopic sinus surgery (FESS) is the most exciting recent surgical treatment of sinusitis and nasal polyps. However, the success of this procedure depends on the visual clarity of the surgical field through the endoscope $[1,2]$. The sinonasal mucosa is very vascular, and poor visualization is due to excessive bleeding that leads to complications associated with this procedure [3].

Controlled hypotension is defined as a reduction in the mean arterial blood pressure to 50-60 mm Hg in a normotensive subject [4]. Controlled hypotension has many advantages for FESS including reduction in blood loss and improved quality of the surgical field. Multiple agents have been used to achieve controlled hypotension, e.g. magnesium sulfate, vasodilators (e.g., sodium nitroprusside), nitroglycerine, high doses of potent inhaled anesthetics, and $\beta$-adrenergic antagonist [5-7]. Studies show that using $\beta$-blockers before surgery reduces long-term cardiovascular complications and intraoperative bleeding $[8,9]$. It is believed that $\beta$-blockers are responsible for improvement of the cardiovascular condition and patients' hemodynamic stability via changes in stress-related physiological response [10]. Data regarding this issue are limited in the literature with a few studies [11-14] that examined the usage of $\beta$-blockers to control blood pressure and improve hemodynamic parameters and visual clarity during endoscopic sinus surgery. The aim of this study was to determine whether the routine use of $\beta$-blockers as a premedication could improve the operative field in ESS. We show that metoprolol significantly improves visual clarity and hemodynamic parameters during FESS.

\section{Patients and Methods}

\section{Inclusion and Exclusion Criteria}

Sixty patients including both male and female patients (physical status I and II as described by the American Association of Anesthesiologists; ASA), aged 18-50 years, undergoing septoplasty and FESS were included in this prospective, randomized, double-blind, placebocontrolled study. Standard FEES was performed including removal of the uncinate process, opening of the anterior ethmoid air cells and Haller cells as well as widening of the maxillary ostium if necessary, and if any polyp was obstructing ventilation or drainage, it was also removed. Then, posterior ethmoidectomy was done. Among patients with deviated nasal septum, endoscopic septoplasty was performed as a preliminary step for FEES. All surgical procedures were done by the same surgeon.

The study did not include patients with pregnancy, cardiac failure, chronic hypotension, patients with asthma, chronic obstructive airway disease, and emphysema, patients with blood system pathology, coagulation disorder, anemia $(\mathrm{Hb}<10 \mathrm{~g} / \mathrm{dL})$, those on medications affecting their coagulation system, and patients with kidney or liver dysfunctions. 
Sadek et al.: Metoprolol Improves Hemodynamic Parameters during Sinus Surgery

\section{Study Design}

The study was conducted at Minia University Hospital, during the period from July to December 2017 after obtaining informed consent from patients and approval of the local ethics committee. The research was conducted ethically in accordance with the World Medical Association Declaration of Helsinki.

Sample size calculation was based on keeping the mean arterial pressure (MAP) between 50 and $60 \mathrm{~mm} \mathrm{Hg}$. The calculation determined that 60 patients (30 in each group) would be required for a study with a power of 1 and an $\alpha$ of 0.05 set for significance. Before surgery, the patients' blood cell count, urea, serum creatinine, and prothrombin time were examined.

Patients were randomly assigned through computer-generated numbers to receive either metoprolol (Betaloc tablets $100 \mathrm{mg}$, AstraZeneca, Egypt) (group 1) or a placebo tablet (a vitamin tablet that was identical to metoprolol in appearance) (group 2) 60 min before surgery.

\section{Anesthesia Regimen}

All patients were kept nil per oral the night before surgery and received oral alprazolam (0.25-0.5 mg) in the night before surgery and $2 \mathrm{~h}$ prior to surgery. Standard monitors including pulse oximeter, noninvasive blood pressure, 5 lead electrocardiogram, end tidal $\mathrm{CO}_{2}$, and temperature probes were attached, and baseline values recorded (Philips monitors, Germany).

All patients received $10-15 \mathrm{~mL} / \mathrm{kg}$ normal saline $(0.9 \%)$ infusion. Patients were first premedicated with an infusion of midazolam $0.05 \mathrm{mg} / \mathrm{kg}$, fentanyl $1 \mu \mathrm{g} / \mathrm{kg}$, and lidocaine $1 \mathrm{mg} / \mathrm{kg}$. All the patients were preoxygenated with $100 \%$ oxygen for $3 \mathrm{~min}$. Induction of anesthesia was achieved with an infusion of propofol $2 \mathrm{mg} / \mathrm{kg}$ and atracurium $0.5 \mathrm{mg} / \mathrm{kg}$, and after 3-5 min, patients were intubated with the appropriate tube size. Anesthesia was maintained with isoflurane $1.5 \%$, atracurium with incremental dose $0.15 \mathrm{mg} / \mathrm{kg}$ every $30 \mathrm{~min}$ and $50 \mu \mathrm{g}$ of fentanyl per hour. Ventilation was maintained to end-expiratory $\mathrm{CO}_{2}$ tension at $35 \pm 2 \mathrm{~mm}$ Hg (model 23542; Dräger Medical AG \& Co. KGaA, Germany).

The hemodynamic endpoint of anesthetic management was the maintenance of mean blood pressure at 50-60 mm Hg for producing bloodless surgical field. To eliminate observer bias, the operating surgeon and the anesthetist were blinded to whether the patient had been given a $\beta$-blocker. Patients were placed in a $10^{\circ}$ reverse Trendelenburg position to improve venous drainage. Patients in both groups received topical application of a mixture of $4 \mathrm{~mL}$ lignocaine $2 \%$ and $1 \mathrm{~mL}$ of epinephrine 1:1,000 on a well wrung out cotton pledges to the nasal mucous membrane, which was kept in situ for 10-15 min.

After removal of pledges, the lateral nasal wall was infiltrated with $0.5-1 \mathrm{ml}$ of $1 \%$ lignocaine with epinephrine 1:100,000-200,000 dilution before commencement of surgery.

At the end of surgery, administration of the anesthetic agent was discontinued, and neuromuscular blockade was reversed using atropine sulfate at a dose of $0.02 \mathrm{mg} / \mathrm{kg}$ i.v. plus neostigmine $(0.05 \mathrm{mg} / \mathrm{kg})$ i.v. Endotracheal extubation was done after the return of adequate muscle tone, power, protective reflex (cough), and when the breathing pattern of patient was smooth. Patients were observed every $15 \mathrm{~min}$ for $2 \mathrm{~h}$ for $\mathrm{SpO}_{2}$, pulse rate, blood pressure, sedation score, visual analogue scale (pain), nausea and vomiting, complications and adverse effects, if any, were recorded.

\section{Measured Parameters}

(1) Hemodynamics (heart rate and MAPs were recorded immediately prior to induction of anesthesia and subsequently every $3 \mathrm{~min}$ for $15 \mathrm{~min}$ and then every $15 \mathrm{~min}$ until the termination of anesthesia). (2) Amount of blood loss. Total blood loss during surgery was calculated from the fluid volume of the suction canister. The volume of irrigating fluid was subtracted from the total volume of fluid collected in the suction bottle. A fully soaked 


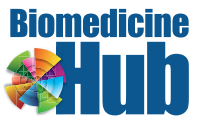

Table 1. Demographic and clinical data of the study groups

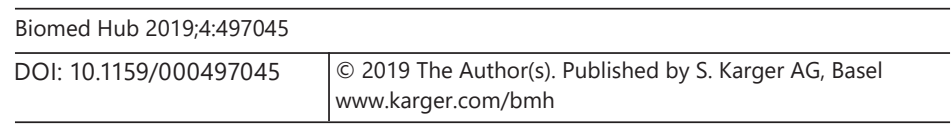

\begin{tabular}{llll}
\hline Variable & $\begin{array}{l}\text { Metoprolol group } \\
(n=30)\end{array}$ & $\begin{array}{l}\text { Placebo group } \\
(n=30)\end{array}$ & $\begin{array}{l}p \\
\text { value }\end{array}$ \\
\hline $\begin{array}{l}\text { Age, years } \\
\text { Sex }\end{array}$ & $31.6 \pm 6.91[18-50]$ & $33.8 \pm 7.2[18-50]$ & 0.722 \\
$\quad$ Male & $16(53.3)$ & $14(46.7)$ & 0.416 \\
$\quad$ Female & $14(46.7)$ & $16(53.3)$ & \\
ASA & $13(43.3)$ & $14(46.7)$ & 0.174 \\
$\quad$ I & $17(56.7)$ & $16(53.3)$ & \\
$\quad$ II & $70 \pm 15.7[31-99]$ & $73.9 \pm 11.8[52-103]$ & 0.27 \\
\hline
\end{tabular}

Data are presented as mean \pm standard deviation [range] or $n(\%)$.

cotton strip was estimated to contain $5 \mathrm{~mL}$ of blood and partially soaked one to contain 2$3 \mathrm{~mL}$ of blood. (3) Surgical time was recorded from the first injection of regional anesthetic to the end of surgery. (4) Surgeon's assessment of operative field condition, the quality scale proposed by Fromme-Boezaart surgical field grading $[15,16]$ was as follows: Grade 0: no bleeding. Grade 1: slight bleeding - no blood suctioning required. Grade 2: slight bleeding - occasional suctioning required. Grade 3: slight bleeding - frequent suctioning required; operative field is visible for some seconds after evacuation. Grade 4: moderate bleeding - frequent suctioning required; operative field is only visible immediately after evacuation. Grade 5: severe bleeding - constant suctioning required; bleeding appears faster than can be removed by suction; surgery is hardly possible, and sometimes impossible.

\section{Statistical Analysis}

Analyses were done for parametric quantitative data between the two groups using the independent-sample Student $t$ test and for nonparametric quantitative data using the MannWhitney test. Analyses were done for qualitative data between the two groups using the Fisher exact test.

\section{Results}

Sixty ASA physical status I or II patients, scheduled for FESS were included in the study and randomly allocated to either the metoprolol group (group 1) or the placebo group (group 2 ). Twenty-four patients (10 in group 1 and 14 in group 2) underwent endoscopic septoplasty because of septal deviation as a preliminary step for the FESS approach. The age, gender, body weight, and ASA physical status were comparable between the two groups (Table 1).

\section{Blood Loss and Surgical Field}

The average blood loss was significantly greater in the placebo group compared to that in the metoprolol group. The duration of surgery was slightly shorter in the metoprolol group. However, the difference was not statistically significant (Table 2).

The surgical field was graded by the surgeon using the Fromme-Boezaart grading scale, and there was a statistically significant difference between those who received metoprolol and those in the placebo group (Table 3). 
Table 2. Duration of surgery and amount of blood loss

\begin{tabular}{lccl}
\hline Variable & $\begin{array}{l}\text { Metoprolol group } \\
(n=30)\end{array}$ & $\begin{array}{l}\text { Placebo group } \\
(n=30)\end{array}$ & $p$ value \\
\hline $\begin{array}{l}\text { Duration of surgery, min } \\
\text { Amount of blood loss, } \mathrm{mL}\end{array}$ & $\begin{array}{c}88 \pm 15.3[70-124] \\
100 \pm 20[90-200]\end{array}$ & $\begin{array}{c}90 \pm 12.9[68-118] \\
125.6 \pm 25.9[100-190]\end{array}$ & $\begin{array}{l}0.622 \\
0.74\end{array}$ \\
\hline
\end{tabular}

Data are presented as mean \pm standard deviation [range].

Table 3. Surgical field as graded by the surgeon according to the Fromme-Boezaart grading scale

\begin{tabular}{lcll}
\hline $\begin{array}{l}\text { Fromme- } \\
\text { Boezaart } \\
\text { grade }\end{array}$ & $\begin{array}{l}\text { Metoprolol group } \\
(n=30)\end{array}$ & $\begin{array}{l}\text { Placebo group } \\
(n=30)\end{array}$ & $p$ value \\
\hline 0 & $0(0)$ & $0(0)$ & \\
1 & $17(56.7)$ & $0(0)$ & \\
2 & $13(43.3)$ & $12(40)$ & 0.0001 \\
3 & $0(0)$ & $10(33.3)$ & \\
4 & $0(0)$ & $0(26.7)$ & \\
5 & $0(0)$ & & \\
\hline
\end{tabular}

\section{Hemodynamic Parameters}

Regarding MAP, the metoprolol group showed no statistically significant difference when compared to control at basal measurement up to $30 \mathrm{~min}$ after induction of anesthesia. MAP was significantly lower in group 1 compared to group 2 from 30 min of induction up to end of surgery (Table 4). The heart rate was significantly lower in those who received metoprolol before the operative procedures (Table 5).

\section{Discussion}

In this study, using a pre- and intraoperative medication regimen, we show that metoprolol significantly improves visual clarity and hemodynamic parameters during FESS. Induced hypotension can be achieved by multiple pharmacological agents. In addition to these agents, we chose to administer a metoprolol $100 \mathrm{mg}$ tablet to 30 patients included in the study (group 1) compared to the other half of patients receiving a placebo (group 2). In our study, there were no reported cases of drug allergy or hypersensitivity and no postoperative hemorrhage.

Metoprolol is known to slow the heart rate, reduce myocardial contractility, and to have an indirect effect on MAP. Also, improved surgical field may be attributed to the vasoconstriction of the mucous membrane of arterioles and precapillary sphincters resulting from unopposed adrenergic effects of endogenous catecholamines.

During FESS, minor bleeding can markedly compromise an already restricted surgical field, which could lead to complications such as injury to the brain and eye globe, and interfere with the completion of a successful surgical procedure [14]. Induced hypotension decreases intraoperative bleeding and improves visibility of the operative field. Multiple factors can influence the surgical field, including physical status of the patient, concomitant disease such 
Table 4. MAP changes in the study groups ( $\mathrm{mm} \mathrm{Hg}$ )
(C) 2019 The Author(s). Published by S. Karger AG, Basel www.karger.com/bmh

Sadek et al.: Metoprolol Improves Hemodynamic Parameters during Sinus Surgery

\begin{tabular}{clll}
\hline \multicolumn{1}{l}{ Time } & $\begin{array}{l}\text { Metoprolol } \\
\text { group }(n=30)\end{array}$ & $\begin{array}{l}\text { Placebo } \\
\text { group }(n=30)\end{array}$ & $\begin{array}{l}p \\
\text { value }\end{array}$ \\
\hline $\begin{array}{l}\text { Baseline measurement } \\
\text { Post-induction }\end{array}$ & $70.65 \pm 6.67$ & $72 \pm 6.49$ & 0.867 \\
$3 \mathrm{~min}$ & $69.85 \pm 6.69$ & $73.8 \pm 8.06$ & 0.657 \\
$6 \mathrm{~min}$ & $67.45 \pm 8.31$ & $65.85 \pm 6.17$ & 0.494 \\
$9 \mathrm{~min}$ & $67.1 \pm 8.77$ & $67.45 \pm 9.17$ & 0.903 \\
$12 \mathrm{~min}$ & $66.35 \pm 8.22$ & $64.15 \pm 6.76$ & 0.187 \\
$15 \mathrm{~min}$ & $64.65 \pm 6.61$ & $68.75 \pm 9.38$ & 0.120 \\
$30 \mathrm{~min}$ & $65 \pm 8.22$ & $66.95 \pm 5.55$ & 0.639 \\
$45 \mathrm{~min}$ & $57.3 \pm 5.97$ & $67.25 \pm 7.27$ & $\mathbf{0 . 0 0 0 1}$ \\
$60 \mathrm{~min}$ & $55.3 \pm 7.26$ & $68.25 \pm 6.98$ & $\mathbf{0 . 0 0 0 1}$ \\
$75 \mathrm{~min}$ & $55.45 \pm 9.08$ & $65.5 \pm 6.26$ & $\mathbf{0 . 0 0 0 1}$ \\
$90 \mathrm{~min}$ & $57.4 \pm 7.26$ & $67.25 \pm 7.27$ & $\mathbf{0 . 0 0 0 1}$ \\
$105 \mathrm{~min}$ & $55.15 \pm 4.08$ & $68.25 \pm 6.98$ & $\mathbf{0 . 0 0 0 1}$ \\
$120 \mathrm{~min}$ & $58.15 \pm 1.18$ & $67.45 \pm 9.17$ & $\mathbf{0 . 0 0 0 1}$ \\
\end{tabular}

Data are presented as mean \pm standard deviation.

Table 5. Heart rate changes in the study groups (beats/min)

\begin{tabular}{lrcc}
\hline Time & $\begin{array}{l}\text { Metoprolol group } \\
(n=30)\end{array}$ & $\begin{array}{l}\text { Placebo group } \\
(n=30)\end{array}$ & $p$ value \\
\hline $\begin{array}{l}\text { Baseline measurement } \\
\text { Post-induction }\end{array}$ & $60.65 \pm 6.67$ & $72 \pm 6.49$ & $\mathbf{0 . 0 0 0 1}$ \\
3 min & $62.85 \pm 6.69$ & $73.8 \pm 8.06$ & $\mathbf{0 . 0 0 0 1}$ \\
6 min & $65.45 \pm 8.31$ & $70.85 \pm 6.17$ & $\mathbf{0 . 0 0 0 1}$ \\
9 min & $67.1 \pm 8.77$ & $77.45 \pm 9.17$ & $\mathbf{0 . 0 0 0 1}$ \\
12 min & $66.35 \pm 8.22$ & $79.15 \pm 6.76$ & $\mathbf{0 . 0 0 0 1}$ \\
30 min & $64.65 \pm 6.61$ & $78.75 \pm 9.38$ & $\mathbf{0 . 0 0 0 1}$ \\
45 min & $65 \pm 8.22$ & $76.95 \pm 5.55$ & $\mathbf{0 . 0 0 0 1}$ \\
60 min & $63.3 \pm 5.97$ & $77.25 \pm 7.27$ & $\mathbf{0 . 0 0 0 1}$ \\
75 min & $62.3 \pm 7.26$ & $78.25 \pm 6.98$ & $\mathbf{0 . 0 0 0 1}$ \\
90 min & $61.45 \pm 9.08$ & $75.5 \pm 6.26$ & $\mathbf{0 . 0 0 0 1}$ \\
105 min & $62.4 \pm 7.26$ & $77.25 \pm 7.27$ & $\mathbf{0 . 0 0 0 1}$ \\
120 min & $63.15 \pm 4.08$ & $78.25 \pm 6.98$ & $\mathbf{0 . 0 0 0 1}$ \\
\hline
\end{tabular}

Data are presented as mean \pm standard deviation.

as bleeding disorders, obesity, and systolic hypertension [17]. Injected vasoconstrictors can lead to serious side effects. After injection of lignocaine with adrenaline, plasma levels of adrenaline reach a peak value that is highly variable and not related to the amount injected into the nasal mucosa [18]. Also, with topical anesthesia with cocaine, idiosyncratic absorption can occur. Toxicity may result in central nervous system stimulation or depression and respiratory failure [19]. Induced hypotension achieved by using only inhalation or intravenous anesthetic agents requires the application of higher doses, which causes longer recovery time. So, in order to achieve the desired level of hypotension in addition to an anesthetic agent, additional hypotensive drugs are the preferred method [20].

Our data show that there was no statistical significance between the metoprolol and placebo groups with regard to the surgical operating time and the amount of surgical bleeding. 
These findings are in accordance with a previous study [14] which investigated 80 patients undergoing endoscopic sinus surgery to receive either $30 \mathrm{mg}$ metoprolol (group 1), or a placebo tablet (group 2) 30 min before surgery.

The quality of surgical field was compared in both groups using Fromme-Boezaart grades. In group 1, 17 patients had grade 1 surgical field and 13 patients had grade 2 surgical field. In group 2, 12 patients had grade 2 surgical field, 10 patients had grade 3 , and 8 patients had grade 4 surgical field. Thus, group 1 (metoprolol) patients had a better quality of surgical field with statistical significance as compared to group 2 (placebo). Our data agree with the findings of a randomized controlled trial performed by Rahimzadeh et al. [21]. Patients entering their study were divided into four groups: $50 \mathrm{mg}$ metoprolol at night before the operation, $50 \mathrm{mg}$ metoprolol on the day of operation, $50 \mathrm{mg}$ metoprolol at night and on the day of the operation, or a placebo. Their results showed that there is a statistical significance between the amount of surgical bleeding and receiving metoprolol ( $p=0.029)$.

HR and MAP were significantly lower in the metoprolol group. These data alone would suggest that the surgical field was likely to be better in the metoprolol group. Another prospective, randomized, double-blind, placebo-controlled trial performed by others [14] is in agreement with our results. Patients were randomly assigned to receive either $100 \mathrm{mg}$ metoprolol (group 1) or a placebo tablet (group 2) $30 \mathrm{~min}$ before surgery. Their 2-h data showed statistically significant difference between the metoprolol and placebo groups as regards HR and MAP.

One of the limitations of this study is that it is a single-center study and may not be representative of the general population. Second, we did not use different dose regimens to reach the precise metoprolol regimen. Third, the sample size is somewhat small.

In conclusion, our data show that metoprolol significantly improves visual clarity and hemodynamics during FESS. We would recommend the use of metoprolol in FESS and septoplasty.

\section{Acknowledgment}

We would like to thank Prof. Sayed F. Abdelwahab, Professor of Microbiology and Immunology, Faculty of Medicine, Minia University, for his help during the preparation of the manuscript.

\section{Statement of Ethics}

The study protocol has been approved by Minia University Faculty of Medicine Research Ethics Committee, and all subjects gave their written informed consent before enrollment into the study.

\section{Disclosure Statement}

The authors have no conflicts of interest to declare.

\section{Funding Sources}

This study was supported by personal funds and funds from Minia University. 


\section{Author Contributions}

A.A.S., T.A.-M., and M.M. conceived and designed the study, and collected and analyzed the data. M.M., T.A.-M., and A.A.S. wrote the manuscript. A.A.S. performed the surgeries, edited the manuscript and supervised the study.

\section{References}

1 Tewfik MA, Wormald PJ. Ten pearls for safe endoscopic sinus surgery. Otolaryngol Clin North Am. 2010 Aug; 43(4):933-44.

2 Baker AR, Baker AB. Anaesthesia for endoscopic sinus surgery. Acta Anaesthesiol Scand. 2010 Aug;54(7): 795-803.

3 Albu S, Baciut M. Failures in endoscopic surgery of the maxillary sinus. Otolaryngol Head Neck Surg. 2010 Feb; 142(2):196-201.

4 Lavoie J. Blood transfusion risks and alternative strategies in pediatric patients. Paediatr Anaesth. 2011 Jan; 21(1):14-24.

5 Degoute CS, Ray MJ, Manchon M, Dubreuil C, Banssillon V. Remifentanil and controlled hypotension; comparison with nitroprusside or esmolol during tympanoplasty. Can J Anaesth. 2001 Jan;48(1):20-7.

6 Elsharnouby NM, Elsharnouby MM. Magnesium sulphate as a technique of hypotensive anaesthesia. Br J Anaesth. 2006 Jun;96(6):727-31.

7 Degoute CS, Dubreuil C, Ray MJ, Guitton J, Manchon M, Banssillon V, et al. Effects of posture, hypotension and locally applied vasoconstriction on the middle ear microcirculation in anaesthetized humans. Eur J Appl Physiol Occup Physiol. 1994;69(5):414-20.

8 Rodrigo C. Induced hypotension during anesthesia with special reference to orthognathic surgery. Anesth Prog. 1995;42(2):41-58.

9 Cincikas D, Ivaskevicius J. Application of controlled arterial hypotension in endoscopic rhinosurgery. Medicina (Kaunas). 2003;39(9):852-9.

10 Mikawa K, Nishina K, Maekawa N. Attenuation of the catecholamine response to tracheal intubation with oral propranolol. Can J Anaesth. 1999;42:829-34.

11 Puthenveettil N, Rajan S, Kumar L, Nair SG. A comparison of effects of oral premedication with clonidine and metoprolol on intraoperative hemodynamics and surgical conditions during functional endoscopic sinus surgery. Anesth Essays Res. 2013 Sep-Dec;7(3):371-5.

12 Jiwanmall M, Joselyn AS, Kandasamy S. Intravenous clonidine as a part of balanced anaesthesia for controlled hypotension in functional endoscopic sinus surgery: A randomised controled trial. Indian J Anaesth. 2017 May; 61(5):418-23.

13 Panda N, Verma RK, Panda NK. Efficacy and safety of high-concentration adrenaline wicks during functional endoscopic sinus surgery. J Otolaryngol Head Neck Surg. 2012 Apr;41(2):131-7.

14 Nair S, Collins M, Hung P, Rees G, Close D, Wormald PJ. The effect of beta-blocker premedication on the surgical field during endoscopic sinus surgery. Laryngoscope. 2004 Jun;114(6):1042-6.

15 Fromme GA, MacKenzie RA, Gould AB Jr, Lund BA, Offord KP. Controlled hypotension for orthognathic surgery. Anesth Analg. 1986 Jun;65(6):683-6.

16 Boezaart AP, van der Merwe J, Coetzee A. Comparison of sodium nitroprusside- and esmolol-induced controlled hypotension for functional endoscopic sinus surgery. Can J Anaesth. 1995;42(5 Pt 1):373-6.

17 Scholtes JL. Deliberate hypotension for middle ear microsurgery. Acta Anaesthesiol Belg. 1981;32(3):195211.

18 John G, Low JM, Tan PE, van Hasselt CA. Plasma catecholamine levels during functional endoscopic sinus surgery. Clin Otolaryngol Allied Sci. 1995 Jun;20(3):213-5.

19 Liao BS, Hilsinger RL Jr, Rasgon BM, Matsuoka K, Adour KK. A preliminary study of cocaine absorption from the nasal mucosa. Laryngoscope. 1999 Jan;109(1):98-102.

20 Lam AM, Gelb AW. Cardiovascular effects of isoflurane-induced hypotension for cerebral aneurysm surgery. Anesth Analg. 1983 Aug;62(8):742-8.

21 Rahimzadeh P, Faiz SH, Alebouyeh MR. Effects of premedication with metoprolol on bleeding and induced hypotension in nasal surgery. Anesth Pain Med. 2012;1(3):157-61. 